\title{
FAILURE TEST OF A SUSPENDOME DUE TO CABLE RUPTURE
}

\author{
Zhi-Hua Chen ${ }^{1,2}$, Xiao-Xiang Wang ${ }^{2,3}$, Hong-Bo Liu ${ }^{1,2, *}$ and Yu-Jie Yu \\ ${ }^{1}$ State Key Laboratory of Hydraulic Engineering Simulation and Safety, Tianjin University, Tianjin 300072, China \\ ${ }^{2}$ School of Civil Engineering, Tianjin University, Tianjin 300072, China \\ ${ }_{3}^{3}$ Department of Civil Engineering and Engineering Mechanics, Columbia University, New York 10027, NY, USA \\ *(Corresponding author: E-mail: hbliu@tju.edu.cn)
}

\section{A B S T R A C T}

Suspendome integrates a lower cable-strut tensegrity system below the upper single-layer latticed dome for long span overlapping. Cable rupture, especially hoop cable failure, is an important failure mode that involves transient cable failure with significant impact. In this study, two kinds of cable rupture tests were conducted on a suspendome model to investigate the dynamic responses, failure modes, and mechanical changes. One was cable rupture at static loading state for simulating the practical cable break condition during the in-service period. The other was single hoop cable tension and rupture for exploring the influence of pretension level and cable-strut joint resistance. Results indicated that the stiffness and robustness of the suspendome were good such that no apparent deflection or failure phenomenon was observed. Cable rupture involved sudden tension failure, which led to the oscillatory response to adjacent strut members. Cable sliding occurred under large tension gaps, and it caused extensive tension loss throughout the entire hoop, thereby leading to different cable tension recovery patterns from non-slip numerical simulations. Cable rupture at the outmost ring had a larger impact and tension loss effect than that at the inner rings, and the extent of its influence on the suspendome was closely related to the tension levels and cable-strut joint characteristics.

\section{ART I C LE H I S T O RY}

$\begin{array}{ll}\text { Received: } & \text { 12 April } 2017 \\ \text { Revised: } & \text { 8 August } 2017 \\ \text { Accepted: } & \text { 17 December } 2017\end{array}$

\section{K E Y W O R D S}

\author{
Suspendome; \\ Cable rupture; \\ Robustness; \\ Cable-strut joint; \\ Oscillatory response
}

\section{Introduction}

Suspendome is a type of hybrid structure that integrates a lower cable-strut tensegrity system below the upper single-layer latticed dome, thereby strengthening the upper shell for long span overlapping. Since the proposal by Kawaguchi, this structure system has been quickly studied and used in many large-span roof systems for public gymnasiums and stadiums due to its high structural efficiency (Kawaguchi et al. [1]; Guo et al. [2]; Liu et al. [3]). Suspendome involves high tension cable systems for improved structural rigidity. Previous experimental studies have indicated that the tensegrity systems in the lower part of the structure significantly influence the boundary reaction and internal force of the upper shell members (Chen [4]; Wang et al. [5]). Therefore, given the importance of cable force in suspendome, many studies have been conducted on force finding, optimism design, and construction control theory. Kang et al. [6] proposed a simplified pretension design method based on static equilibrium and found that the outmost ringstiffened suspendome is the most efficient. Subsequently, Cao and Zhang [7] found that the outmost ring generally exhibits the highest tension level and the greatest influence on structural performance after a series of force finding analyses. The cable stretching process imposes a considerable influence on the upper shell due to the hybrid construction of suspendomes, and the effect in turn affects the pretension introduction in sub cable systems. Chen et al. [8] indicated that the pretension force of latterly stretched cables influences previously finished cables, and the influencing pattern differs from the comparative locations of hoop cables. Liu and Chen [9] studied the hoop cable stretching process and found that the pre-stressing loss induced by sliding friction during pre-stressing construction exerts a remarkable effect on the mechanical behavior of suspendomes. These findings were validated by the construction process of the Badminton Stadium suspendome for the 2008 Beijing Olympics (Wang et al. [10]). Further studies on form findings and construction control have greatly helped in evaluating and guiding structural designs (Zhang et al. [11]). However, the structural degradation or failure evaluation is crucial because of the wide application of suspendome in public buildings. The structural response under cable rupture requires special consideration, especially for the cable incorporated hybrid type. However, this area remains in the preliminary stage.

In suspendomes, tensioned cables may experience accidental damages or rupture scenarios during their service period due to construction errors or human factors. In addition, cable failure will not only result in the sudden failure of structural components but also involve a considerable unloading effect on the remaining structure owing to the high-tension state (Wang and Bai [12]; Gerasimidis and Baniotopoulos [13]). Chen and Sun [14] explored the internal force distribution pattern and the nonlinear stability behavior of suspendomes before and after cable failure by directly running static simulation with or without ruptured cable pieces. Their results indicated that a ruptured hoop introduces its load bearing share to the upper shell and surrounding members, and the outmost ring exerts the largest influence on internal force redistribution.
Zhu et al. [15] performed a cable rupture failure analysis of a cable dome and a suspendome and found that hoop cable rupture in a cable dome leads to large nodal displacements and structural slacking, whereas the suspendome does not experience collapse because of the restraint of the rigid upper shell. However, member forces that surround the rupture point present dramatic variations, with the oscillation extent exceeding three times that of the original stress state. Wang et al. [16] studied the cable breaking problems during construction and operation stages and then evaluated the vulnerable cable parts. Considerable discussion on cable rupture effect has been mainly numerical explorations. Liu et al. [17] recently performed a rupture test on annular crossed cable-truss and found an obvious deflection increase in cable-truss under cable rupture. However, related experimental data are rare as a result of the operation difficulties in suspendome failure tests under cable rupture and the high dynamic reaction measurement requirements.

In this study, the cable rupture response of a suspendome model was experimentally investigated. The experiments were designed to identify the effect of cable loss and the safety of suspendomes under the condition of sudden breakage of critical cables and study the effect of cable sliding on the internal force redistribution behavior. Two impact cases were considered, namely, single hoop cable breaking under normal service conditions and rupture responses with only one tensioned hoop cable under self-weight. The strain histories, dynamic deformations, and member-moving procedures were recorded and identified to study the dynamic reactions and cable rupture effects.

\section{Experimental preparation}

\subsection{Experimental background and general conditions}

The tests were performed on a suspendome model, which was designed based on the 10:1 scaled-down design of a real stadium roof with a $108 \mathrm{~m}$ span (Fig. 1(a)). The real structure, Chiping Gymnasium (Liu and Chen [9]), adopted the suspendome design with a stacked arch (Fig.1(b)), whereas the test model only retained the dome part that comprised a K6 lamella single-layer reticulated shell and a sub-tensegrity system with seven hoop cables (Fig.s 1(c) and (d)). The dome span was $10.8 \mathrm{~m}$, and the rise was $2.55 \mathrm{~m}$. The roof model was supported on two circular platforms made of $\mathrm{H}$ section beams. Each ring was seated on 24 evenly distributed $3.25 \mathrm{~m}$-high inner columns and $2.4 \mathrm{~m}$-high outer columns.

The dimensions of the model members were designed based on axial stress consistency with the real structure under static loading conditions, and the availability of practical member size in the market was also considered. The specifications of the model members are listed in Table 1. The Chiping Stadium adopted the hoop-cable-stretching method, which can save on tensioning equipment and improve the stretching consistency. A new type of rolling cablestrut joint was proposed to overcome the cable loss from the friction in the cable-strut joint as shown in Fig. 2(a). Therefore, a simplified rolling joint was 
designed and utilized in the test model (Fig. 2(b)). Detailed information and the effect of this rolling joint were presented by Chen et al. [8]. The cable-strut joint in the model consisted of a center roller for convenient cable sliding during the tensioning process. After tensioning, U-shaped clips were fastened to both sides of the roller to prevent the continuous cable from sliding. Previous static tests have proved the effectiveness of this joint model in resisting the unbalanced cable force under static loading cases. However, the clip may fail to prevent the cable from sliding under significant dynamic disturbance. This effect was carefully monitored during the current failure test.

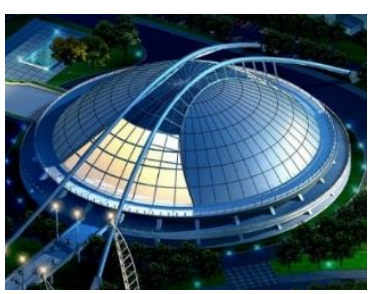

(a) Chiping Gymnasium

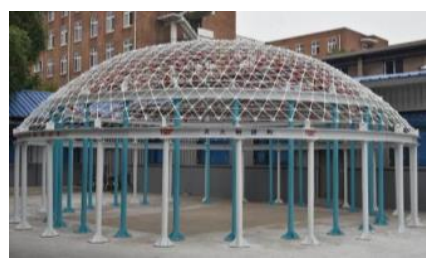

(c) Overview of the test model

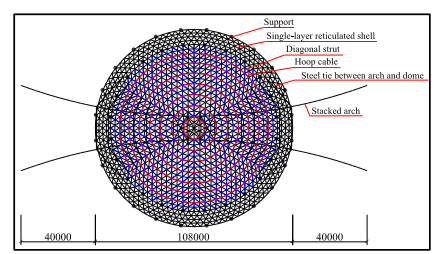

(b) Composition and layout

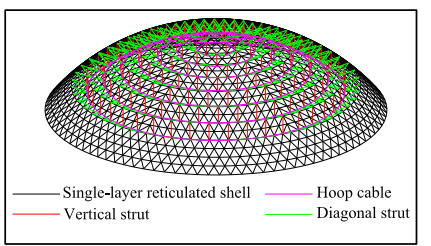

(d) Upper shell and the sub cable-strut system
Fig. 1 Chiping Gymnasium and scaled-down suspendome test model
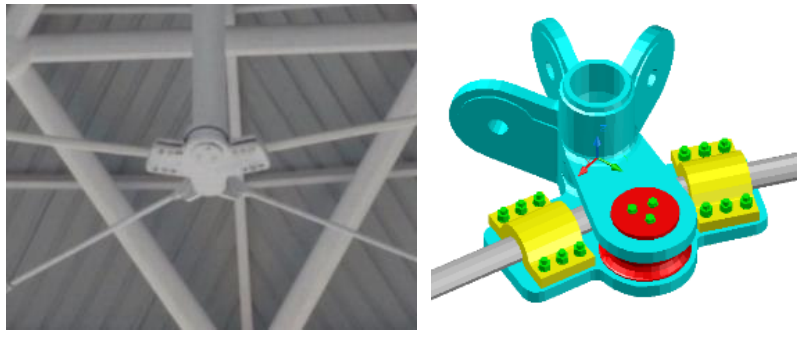

(a) Rolling cable-strut joint in the real structure

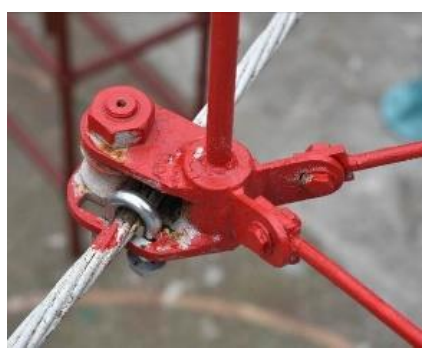

(b) Simplified rolling joint in the test

Fig. 2 Rolling cable-strut joint to reduce pretension loss

Table 1

Specification of the experimental model

\begin{tabular}{|c|c|c|c|c|}
\hline Items & $\begin{array}{l}\text { Porotype } \\
\text { members }\end{array}$ & $\begin{array}{c}\text { Porotype } \\
\text { section area } \\
\left(\mathrm{cm}^{2}\right) \\
\end{array}$ & $\begin{array}{c}\text { Model } \\
\text { members }\end{array}$ & $\begin{array}{c}\text { Model section area } \\
\text { actual/theoretical } \\
\left(\mathrm{cm}^{2}\right)\end{array}$ \\
\hline \multirow{5}{*}{$\begin{array}{l}\text { Single-layer } \\
\text { reticulated } \\
\text { shell }\end{array}$} & $\mathrm{P} 203 \times 6$ & 37.130 & $\mathrm{P} 12 \times 2.5$ & $0.746 / 0.7426$ \\
\hline & $\mathrm{P} 219 \times 7$ & 46.620 & $\mathrm{P} 13 \times 3$ & $0.942 / 0.9324$ \\
\hline & $\mathrm{P} 245 \times 7$ & 52.340 & $\mathrm{P} 16 \times 2.5$ & $1.06 / 1.0468$ \\
\hline & $\mathrm{P} 273 \times 8$ & 66.600 & $\mathrm{P} 17 \times 3$ & $1.319 / 1.332$ \\
\hline & $\mathrm{P} 299 \times 8$ & 73.140 & $\mathrm{P} 19 \times 3$ & $1.508 / 1.463$ \\
\hline $\begin{array}{c}6^{\text {th }} \text { to } 7^{\text {th }} \text { hoop } \\
\text { cable }\end{array}$ & $\Phi 7 \times 73$ & 28.090 & $\begin{array}{l}\text { Steel wire } \\
\text { rope }(\Phi 12)\end{array}$ & $0.5688 / 0.5618$ \\
\hline $\begin{array}{c}1^{\text {th }} \text { to } 5^{\text {th }} \text { hoop } \\
\text { cable }\end{array}$ & $\Phi 7 \times 121$ & 46.570 & $\begin{array}{l}\text { Steel strand } \\
(\Phi 15.24)\end{array}$ & $1.4000 / 0.9314$ \\
\hline Strut & $\mathrm{P} 219 \times 7$ & 46.620 & $\mathrm{P} 13 \times 3$ & $0.942 / 0.9324$ \\
\hline Radial cable & $\Phi 80$ & 50.240 & $\Phi 11.5$ & $1.039 / 1.0048$ \\
\hline
\end{tabular}

\subsection{Experimental apparatus}

The entire testing procedure involved tensioning the hoop cables, applying full-span loads to simulate the working state of the roof, and activating the cable rupture. Therefore, this test required several special apparatuses, which included tensioning devices for applying the pretension, cable-force-measuring devices for obtaining the internal tension state, and a rupture device for simulating the sudden break of the tensioned cable. Fig. 3(a) shows the tension device utilized in the test. The device comprised a pair of channels and long screws, and pretension was applied by tightening the bolts at the long screws. The internal force of the shell members and struts was measured with strain gauges. However, this strain-measuring method could not be directly utilized to obtain the cable tension owing to the multi-wire composition and uneven surface of the cables. A cable force measuring device was then designed (Chen et al. [8]), as shown in Fig. 3(b). The hoop cable was interrupted at the measuring point and then anchored to the two clamps. Therefore, cable tensions were transmitted through measuring devices, and force was obtained through stain measuring at the side plates.

The rupture tests aimed to explore the dynamic effect under cable break impact and suspendome safety with cable break at different circles. Therefore, a rupture device was designed to ensure a cable break at the desired time and location, as shown in Figs. 3(c) and (d). The device mainly consisted of a handle, a cam, and a pair of clips that could clamp the anchorage. The piles and handle were connected by the cam. When pulling the handle, the cam would turn over and open the clips. At the same moment, the clamped anchorage was released, thereby creating a sudden breaking effect.

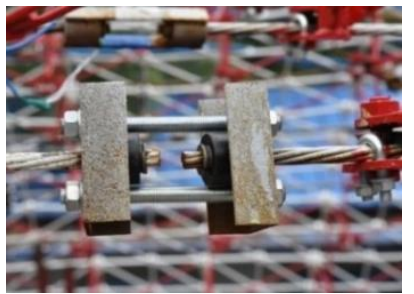

(a) Tensioning device

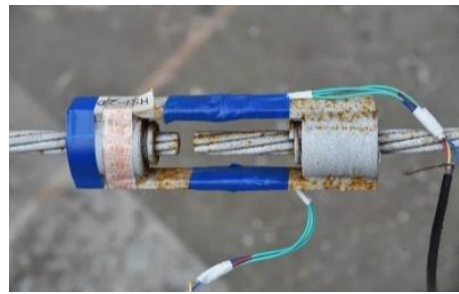

(b) Cable force measuring device

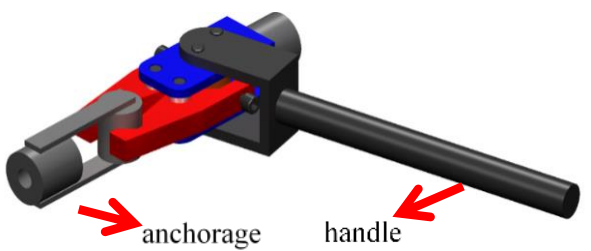

(c) 3D model of cable rupture device

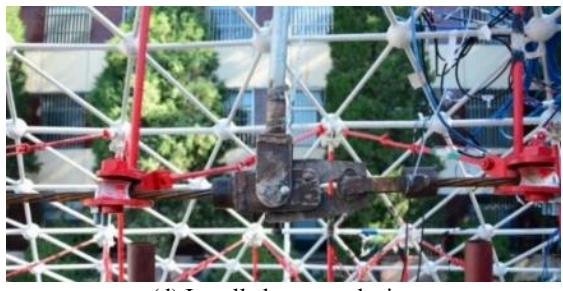

(d) Installed rupture device

Fig. 3 Special apparatuses in the test

\subsection{Cable tensioning, loading, and measuring}

The full-sized roof was designed to bear $0.4 \mathrm{kN} / \mathrm{m} 2$ of dead load during the service period. The real dome has more than a thousand joints. According to load similarity and loading practicability, only 80 nodes were selected as the loading points, and $0.6 \mathrm{kN}$ of vertical load was applied at each node (Fig. 4(c)). Prior to each cable break, the suspendome needed to experience cable tensioning and loading to reach the service state. Similar to the Chiping Stadium, the model employed the hoop cable stretching method, and multiplepoint simultaneous stretching with joint lubrication was adopted to reduce frictional loss and achieve a uniform cable force distribution (Figs. 4(a), (b), and (d)). During cable stretching, the internal forces were recorded by the static strain indicator to control the loading extent and verify the measuring effectiveness. Before the rupture, the strain gauges were shifted to a dynamic strain amplifier (type TST5912, Fig. 5(a)) to capture the dynamic signals. When the cable ruptured, the internal force reactions were transient, with member forces experiencing a dramatic change within a short time. The rupturing region was also filmed by a Y-SERIES high-speed video camera with a recording speed of 500 frames per second during the break stage (Figs. 5(b) and (c)). 


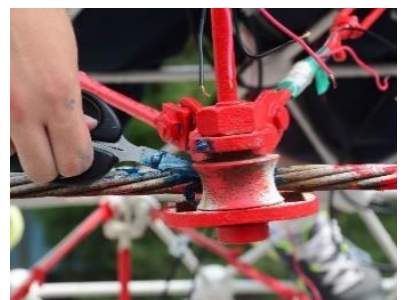

(a) Rolling joint lubrication

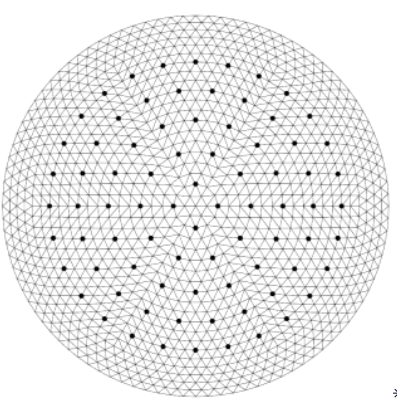

(c) Layout of loading joints

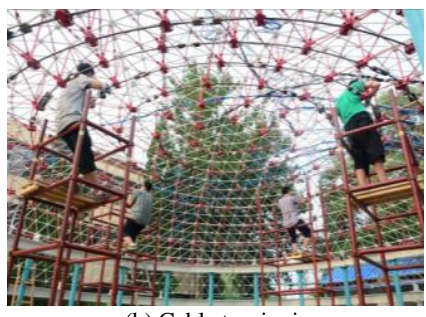

(b) Cable tensioning

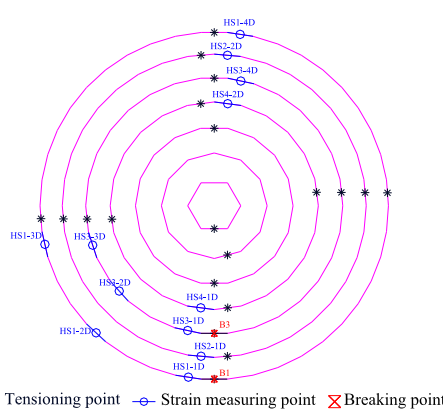

(d) Layout of tensioning and measuring points
Fig. 4 Cable Tensioning and Loading

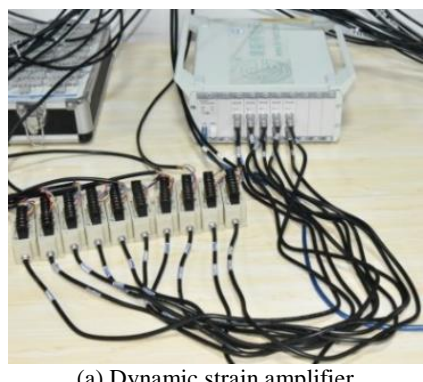

(a) Dynamic strain amplifier

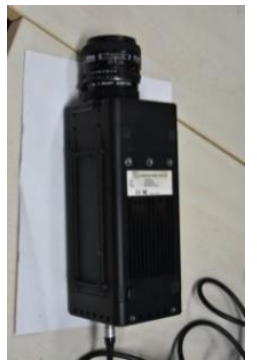

(b) High-speed video camera

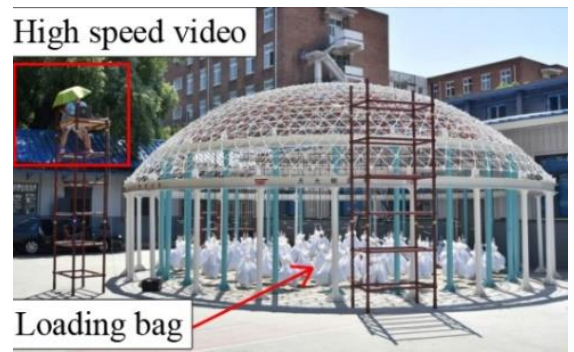

(c) Photo of the rupture test

Fig. 5 Measuring device for dynamic reactions

\subsection{Testing of cable force}

The suspendome model had seven hoop cables, and each ring was numbered first to seventh from outside to inside. The layouts of the tensioning points, rupturing locations, and measuring spots at the hoop cables are shown in Fig. 4(d). Four tensioning points were arranged at the four outer circles (first to fourth hoop), two points at the fifth ring, and one point at the inner sixth and seventh circles. The measuring spots were denoted as HS1-2D, where "HS" represents hoop strands, the first number (e.g., 1) is the number of hoop cable, the second number (e.g., 2) is the sequence number of the measuring spots, and "D" means dynamic.

\subsection{Referencing finite element simulation}

Construction and cable stretching simulations were performed beforehand in ANSYS for the guidance of pretension introduction. In the finite element simulations, pretension introduction was exerted by changing the initial strain of the cable element. However, for cable rupture problems, loss of cable piece and possible sliding behavior involve variation on structural stiffness matrices. Traditional methods of designing and analyzing suspendomes always simplify cable pieces as multi-segment bar or link elements without bending and compression-resisting capabilities. Therefore, common simulations cannot realize the sliding behavior and dynamic effect. In this study, static loading analysis of the suspendome model without the ruptured cable piece was performed to obtain the ultimate interforce distribution in the non-sliding cable case as reference. Then, cable sliding behavior and its effects, dynamic oscillatory response evaluation, and failure extents could be deduced from the comparison between the static simulation and test results. In the referencing simulation, the BEAM188 element was applied to the upper shell members and the supporting column. The LINK8 element was applied to the vertical and diagonal struts, and the LINK10 element was applied to the hoop cables.

\section{Cable rupture during the service state}

\subsection{Break at the third hoop cable}

Fig. 6 shows the variation in cable forces during tensioning. In this rupture case, the stretching strategy adopted an inward tensioning sequence that started from the first circle to the seventh circle. The tensioning spot (B3) became the ruptured location, and two cable ends were connected by the rupture device at this point. The B1 point was an ordinary stretching spot in this case. The inward tensioning strategy was performed in ANSYS, and the values of which were represented by black dash lines. The results showed that cable force measuring devices could effectively reflect the internal forces and their varying trends. For the measured cable pieces close to the stretching end, the cable forces could be controlled well. On the contrary, for the points located between tensioning ends, such as HS1-2D, HS3-1D, and HS3-2D, the obtained forces were comparatively low due to the tension loss at each turning node. The varying trends of cable tension after each stretching step were not exectly the same with the finite element analysis (FEA) curves owing to the effect of friction.

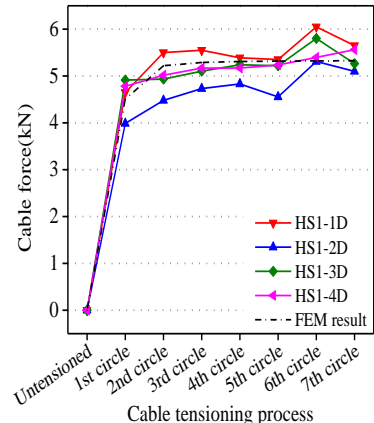

(a) $1^{\text {st }}$ hoop

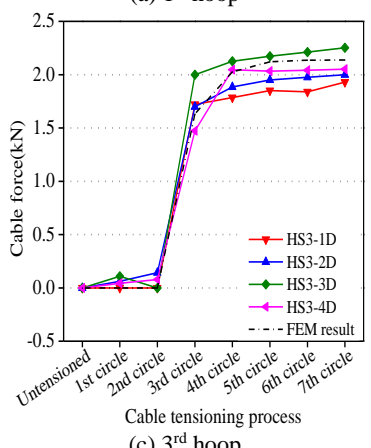

(c) $3^{\text {rd }}$ hoop

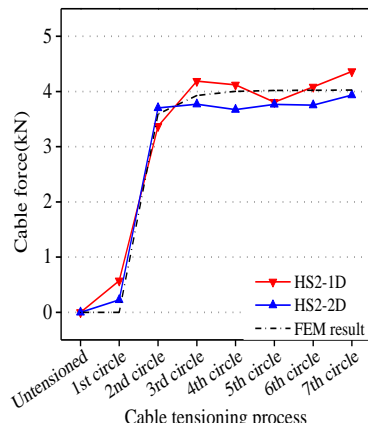

(b) $2^{\text {nd }}$ hoop

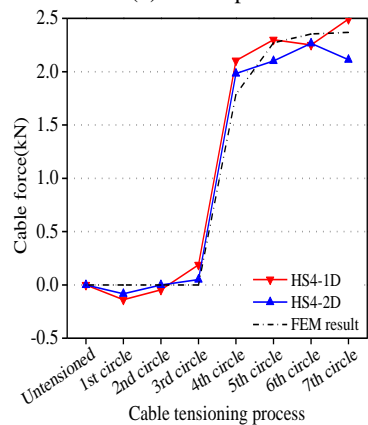

(d) $4^{\text {th }}$ hoop
Fig. 6 Variation in cable force during tensioning

The cable break at the third circle did not induce visible deflection or shaking behavior, except for a slight shrink back effect on the ruptured ends. Fig. 7 shows the dynamic reaction of the selected hoop cables, marking the static simulation results with and without ruptured cable piece as reference (dash lines). For the ruptured cable (third hoop), the segments (HS3-1D) near the break point exhibited an immediate and dramatic decrease in internal force. By contrast, the farthest cable pieces (HS3-4D) experienced insignificant variation, the trends of which were consistent with those in the static simulations. Meanwhile, the measured cable tension for the two other spots was different from the FEA results. HS3-2D presented a small decrease instead of an increasing trend (Fig. 7(c)). Being a certain distance away from the break, the tension force of HS3-3D did not suffer muchfrom cable failure in the static simulation. However, the measured data still displayed tension loss, indicating that tension loss spread to more than half of the circular region. The rupture at the third hoop also led to some tension loss at the second circle (HS2-1D).

The different cable force distributions indicated that the non-sliding assumption was no longer suitable for this model, and the adopted rolling joint failed to completely prevent the continuous cable from sliding. In the nonsliding cable suspendome condition, the hoop cable was separated and no sliding was allowed at the cable-strut joints. Therefore, adjacent cable pieces 
acted as individual segments, with their tension following the force equilibrium principle. When any cable piece ruptured, the remaining cable could be effectively pulled by the diagonal struts, with the absent tension quickly regained. The quick recovery even induced tension increase in the $45^{\circ}-90^{\circ}$ angle regions, which correspond to the breaking spot. While in the test, the measured data presented cable slacking behavior with the gradual recovery of cable tension from the break spot to the farthest side.

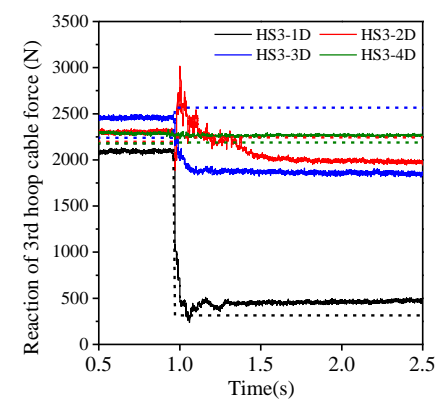

(a) Ruptured cable (third hoop)

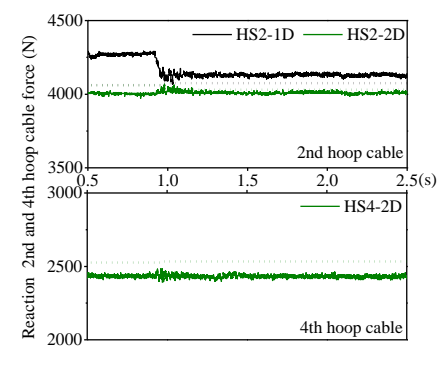

(b) $2^{\text {nd }}$ and $4^{\text {th }}$ hoops

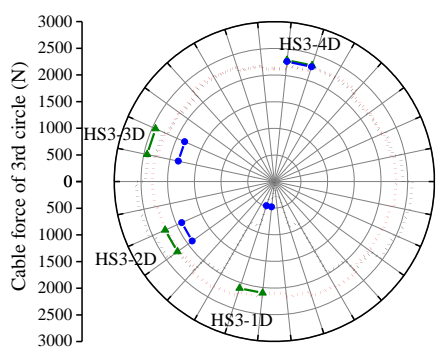

$\begin{array}{ll}\text { FEM before break } & -\wedge-\text { Test before break } \\ \text { FEM after break } & -0 \text { - Test after break }\end{array}$

(c) Comparison of FEM and test

Fig. 7 Variation in cable force during the third circle cable rupture

Fig. 8 shows the filmed images of the ruptured region, and the distance between the ruptured device and the adjacent joints is marked to indicate the cable sliding behavior. Cable broke at time $t=0.80 \mathrm{~s}$. When the clamp was opened, the hoop cable was released suddenly. The distance from the rolling joint to the cable end narrowed from time $t=0.80 \mathrm{~s}$ to $t=0.92 \mathrm{~s}$ and then reversed slightly at time $t=0.98 \mathrm{~s}$. This micro-displacement change, together with the cable force redistribution pattern, indicated that, although fixed with U-shaped clips, cable slip still occurred under a huge tension gap that was induced by the break.

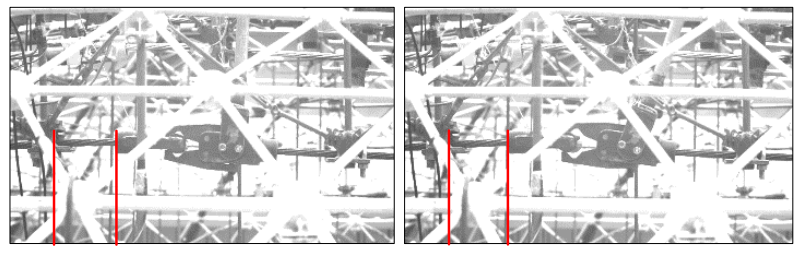

(a) $t=0.80 \mathrm{~s}$

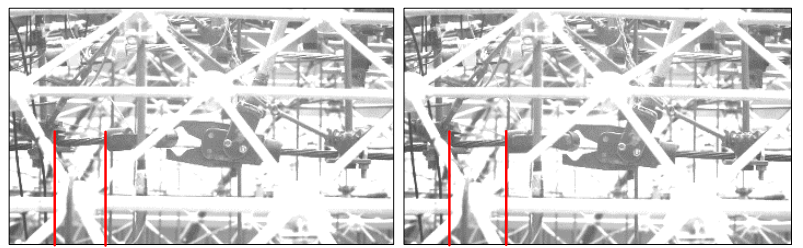

(c) $t=0.92 \mathrm{~s}$

(d) $t=0.98 \mathrm{~s}$

Fig. 8 Typical pictures obtained by the high-speed video camera

Fig. 9 plots the dynamic reactions of the diagonal struts (Fig. 9(b)), vertical struts, and shell members (Fig. 9(c)) close to the ruptured spot. History reactions at critical moments (0.80-1.20 s, gray dot region) were also added separately to present the transient reaction at the rupture moment better. The results indicated that cable slip could also influence the oscillatory response and the forcechanging pattern of adjacent struts. During breaks, induced tension gap caused a significant pulling impulse, thereby leading to sudden tension decrease at DS1. Then, the internal force of DS1 rebounded rapidly and vibrated at a high-tension state (from $-18 \mathrm{MPa}$ to $20 \mathrm{MPa}$ ) to follow the mechanical equilibrium owing to cable sliding and joint friction resistance. The internal force at DS3 exhibited a dramatic increase (from 1.2 $\mathrm{MPa}$ to $38.2 \mathrm{MPa}$ ). The measured force redistribution patterns could also reveal the cable sliding behavior at the two adjacent joints. The significant tension increase at DS3 proved its effective roles in resisting cable sliding and in the pulling trend of the remaining cable.

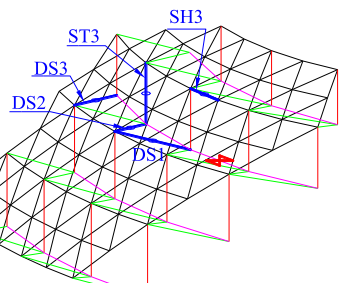

(a) Selected components

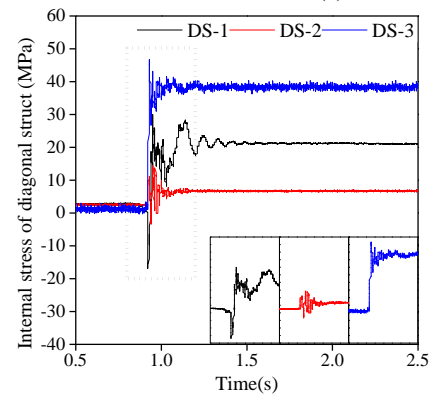

(b) Stress in diagonal strut

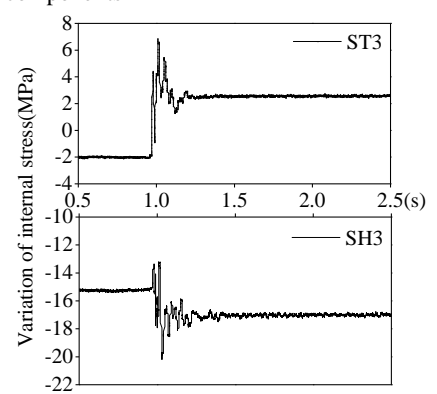

(c) Vertical strut and shell member
Fig. 9 Internal stress variation at struts and shell members during cable rupture

\subsection{Break at the first hoop cable}

After the first rupture case, the dome was unloaded and the cables were loosened to prepare for the subsequent break test. In this case, the break occurred at the first circle. The entire testing process was similar to the previous one but with a different tensioning sequence that started from the seventh circle to the first circle. Fig. 10 shows the cable force variation at the outmost four circles during the entire tension process. The tested result demonstrated a consistent pattern with the FEA simulation results. The tension gradient and variation in the same circle were attributed to the slight friction loss at the cablestrut joint.

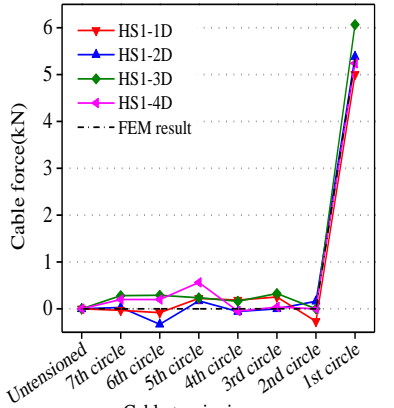

Cable tensioning process

(a) $1^{\text {st }}$ hoop

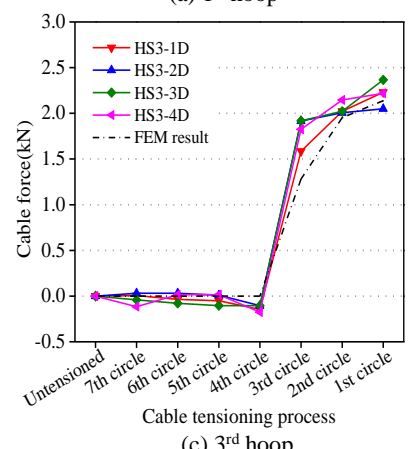

(c) $3^{\text {rd }}$ hoop

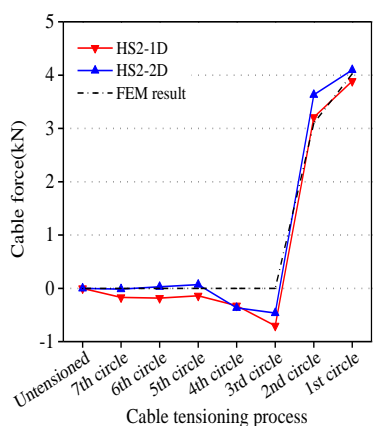

(b) $2^{\text {nd }}$ hoop

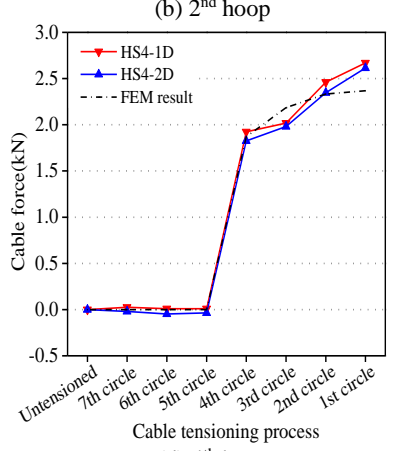

(d) $4^{\text {th }}$ hoop
Fig. 10 Change in cable force during the tensioning process

The break initiation of the first hoop rupture case was harder than that of the previous third hoop break as a result of the high-tension state. The sudden rupture induced a strong perceivable vibration, but no visible deflection or shaking behavior was observed. Given that the outmost ring had the highest tension in the suspendome, the excellent stiffness and robustness performance of this hybrid structure was confirmed. Therefore, single member or cable rupture would not lead to global failure or progressive collapse behavior during the service state. Fig. 11 presents the dynamic response of cable force at the first (ruptured circle), second, and fourth circles, with corresponding static 
simulation data as reference. The tension of HS1-1D decreased with the sudden release of the clamped end and then reversed back at approximately $2500 \mathrm{~N}$. HS1-2D and HS1-3D presented abrupt decreases without significant oscillation contrary to the slight increase in FEA.
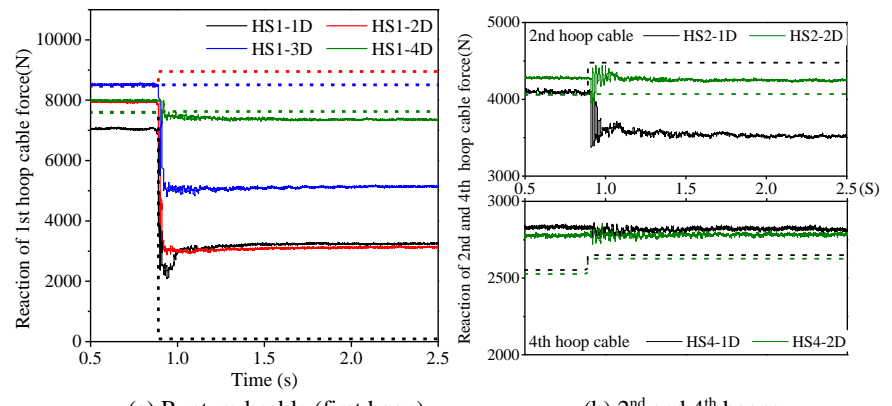

(a) Ruptured cable (first hoop)

(b) $2^{\text {nd }}$ and $4^{\text {th }}$ hoops

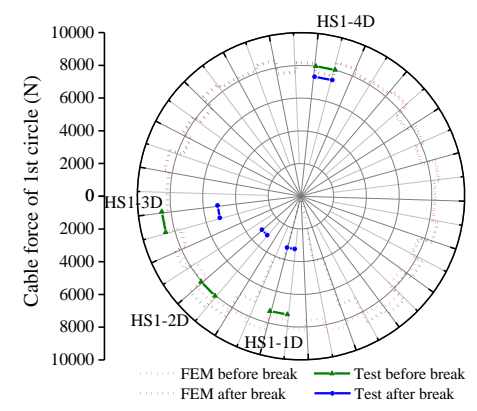

(c) Comparison of FEM and test

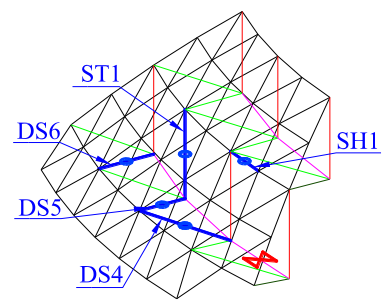

(d) Selected components

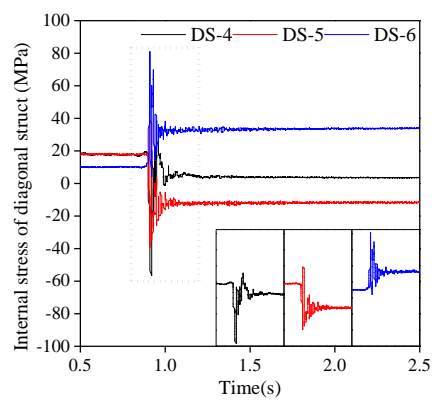

(e) Stress in diagonal strut

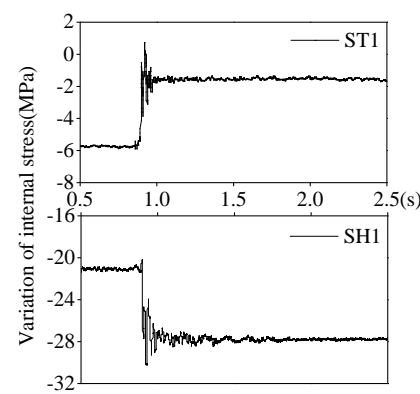

(f) Vertical strut and shell member

Fig. 11 Variation in member force during the first hoop cable rupture

If no sliding was allowed at the cable-strut joint, then the absent tension at the rupture spot would be recovered within a comparatively small region. However, the test data showed that even the cable piece (HS1-3D) located at nearly $90^{\circ}$ away from the break still presented a significant tension loss, indicating a wide range of cable slacking and absent tension recovery behavior. Therefore, the comparison indirectly indicated that joint sliding also occurred at the first hoop break and the influencing range was wider than the third hoop break case due to a high pretension level. In this break case, the rupture not only led to tension force redistribution at the ruptured circle but also caused a strong vibration (HS2-2D) and internal force change at adjacent circles (HS2-1D). The cable tension in the fourth circle did not express significant oscillation behavior, representing a comparatively small influence from the rupture.

The friction resistance and frictional energy dissipation at the cable-strut joints led to weak and quickly dissipating oscillatory response, which subsequently changed the tension state and force redistribution at adjacent cable pieces. Therefore, HS2-1D had an obvious tension decrease instead of increase in the non-slip simulation. DS5 turned into a compression state, and only a slight internal force change was exhibited at DS4 and DS6. The shell member (SH1) presented a large decrease, indicating an unloading effect on the upper shell around the ruptured region.

\subsection{Discussion of the dynamic effect}

The previous discussion showed that the dynamic effects involved in the hoop cable rupture played a significant role in the internal force redistribution of the suspendome structures. For members located far from the ruptured spot or at the low joint-slip exposure region, the dynamic responses were typically high-frequency oscillation. For the struts or cable pieces (such as DS1, DS5, and ST3) that suffered from cable rupture and slight joint shaking influence, the dynamic response exhibited a dramatic and asymmetric change at the ruptured moment. For members around the ruptured spot (such as HS3-1D, DS1, HS11D, and DS4), the significant impact led to a shaking response at the surrounding rolling joints via cable pulling and frictional sliding, thereby resulting in a low-frequency oscillation part embedded in the dynamic responses.

According to references (Wolff and Starossek [18]; Mozos and Aparicio [19]), the dynamic effect from rupture incidents is generally considered with a dynamic amplification factor (DAF) in design and analysis processes, that is,

$$
D A F=\frac{S_{\mathrm{dyn}}-S_{0}}{S_{\text {rest }}-S_{0}}
$$

where $S_{\text {dyn }}$ represents the extreme dynamic responses in time history, $S_{\text {rest }}$ is the rested internal force after the oscillatory effect dissipated, and $S_{0}$ is the initial mechanical state before breaking. In typical design cases, rupture tests are seldom implemented because of the high equipment requirements, and dynamic simulations are not always available. Static member removal analysis is usually performed instead, and a factor of 2.0 is applied as the DAF to account for the dynamic effect. This value is based on the behavior of a linear elastic system with no damping and instantaneous removal and theoretically represents the worst-case scenario (Russell et al. [20]). However, given that it is incapable of considering the damping effect and the cable sliding influence, traditional nonslip static simulation cannot reflect the realistic condition, such as the internal force redistribution at diagonal struts and hoop cables. On the basis of the tested data and the comparison with referencing static simulation, two sets of DAFs were calculated and compared (Eqs. 2 and 3), and they are shown in Fig. 12.

$D A F(t e s t)=\frac{S_{\mathrm{dyn}}(\text { test })-S_{0}(\text { test })}{S_{\text {rest }}(\text { test })-S_{0}(\text { test })}$

$D A F(F E A)=\frac{S_{\mathrm{dyn}}(t e s t)-S_{0}(\text { test })}{S_{\text {rest }}(F E A)-S_{0}(F E A)}$
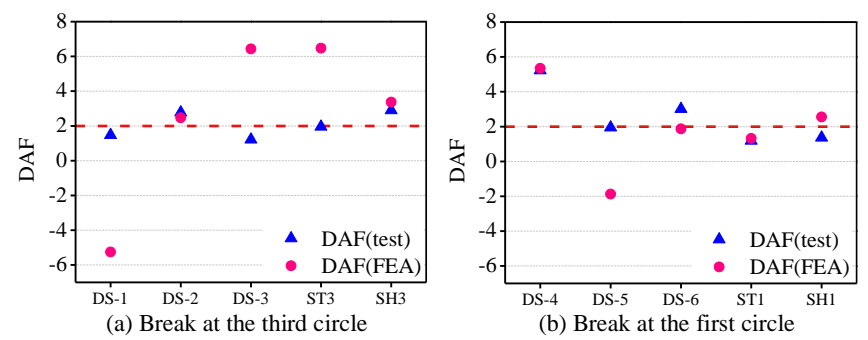

Fig. 12 DAF of selected members

The majority of DAF (test) data fluctuated at approximately 2.0, supporting the reason for this design guidance. However, DAF (test) was calculated on the basis of the test results, the data of which were quite hard to obtain, whereas DAF (FEA) values were more scattered, and some spots were significantly larger than 2.0 or even had negative values (Fig. 12). The difference between the two DAF values and their locations indicated that the scattered spots in both break conditions were mainly diagonal struts directly influenced by cable force redistributions. Like DS1 in the third hoop break and DS4 in the first hoop break case, sudden rupture and induced cable sliding led to different cable force recovery patterns, which then resulted in different denominator variations in Eq. 3 compared with the test data. When analyzing or designing suspendome with rolling joints, special attention or significant safety insurance should be considered for diagonal struts. In addition, further investigations and advanced models are required to account for the dynamic sliding and friction energy dissipation at the rolling joints.

\section{Rupture in the single tensioned cable case}

The preceding discussion indicated that structural dynamic reactions were closely influenced by the tension level of ruptured cables. The results also indicated that the joint sliding behavior and its effect could affect the oscillation response and internal force redistribution patterns. To further investigate the effect of cable frictional sliding on the dynamic response of the suspendome, a series of rupture tests under the single tensioned cable condition was performed. In this case, only the third circle was tensioned, while the rest of the circles were slackened. The friction-resisting capability of the rolling joints was controlled through the tightening of the U-shaped clips in the rolling joints at different 
extents. Different pretension levels and joint-tightening conditions were considered in the test. No external loads were applied. The detailed testing information is listed in Table 2.

Table 2

Parameters of the single cable ruptured test

\begin{tabular}{ccc}
\hline Case Number & Tightening Condition & Pretension $(\mathrm{N})$ \\
\hline A1500 & All fully tightened & 1500 \\
A3000 & All fully tightened & 3000 \\
A6000 & All fully tightened & 6000 \\
H3000 & Half tightened & 3000 \\
N3000 & Non-tightening clips & 3000 \\
\hline
\end{tabular}

The tests could be divided into two parts. The first three cases, A1500, $\mathrm{A} 3000$, and A6000, were all fully fastened conditions, in which all rolling joints were fully fastened under $1500 \mathrm{~N}, 3000 \mathrm{~N}$ and $6000 \mathrm{~N}$ pretension levels at the third hoop cable. The last two cases had $3000 \mathrm{~N}$ cable tension but $\mathrm{H} 3000$ was loosely fastened at the cable-strut joints (half tightened), whereas N3000 had no clips at all. A3000, H3000, and N3000 could be compared to understand the joint effect on the overall dynamic behavior of the suspendome.

In the $\mathrm{A} 1500$ and $\mathrm{A} 3000$ cases, cable rupture did not produce a perceivable vibration effect. In the A6000 case, the adjacent joints expressed slight oscillation and a separating trend with the release of the cable ends. For the H3000 and N3000 tests, the breaking of hoop cable led to obvious cable sliding, accompanied by slight vibrations at the rolling joints and diagonal struts.

Fig. 13 shows the typical behavior of the ruptured region at the initial state and the largest response moment. Fig. 14 displays the residual sliding conditions after the test. No apparent sliding was observed in the fully fastened condition, even for the A6000 test. Slight member vibrations were observed as the cable tension increased to a high level. In the H3000 and N3000 tests, the remaining cable shrank obviously and slid across the rolling joints with the release of the cable end. The joint friction also induced a slight oscillation effect at the adjacent members during the rupturing period. $\mathrm{N} 3000 \mathrm{had}$ a larger sliding extent and a more violent perceivable shaking behavior at the dome than those of $\mathrm{H} 3000$.

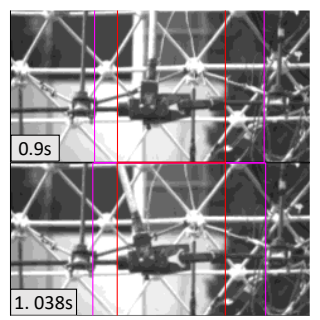

(a) $\mathrm{A} 6000$

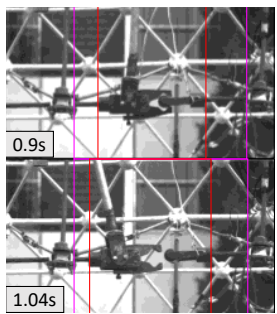

(b) $\mathrm{H} 3000$

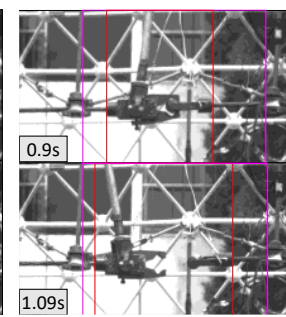

(c) N3000
Fig. 13 Typical photos captured by the high-speed camera before and after cable rupture

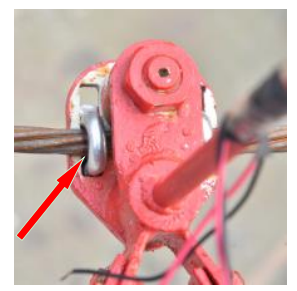

(a) $\mathrm{A} 6000$

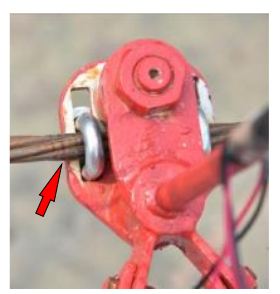

(b) $\mathrm{H} 3000$

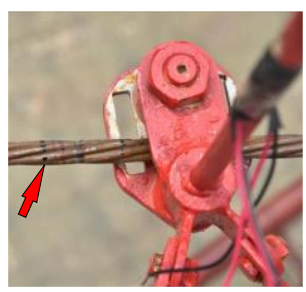

(c) $\mathrm{N} 3000$
Fig. 14 Residual joint slip after the test

Prior to each test, the clip locations were marked at the ruptured hoop cable. Then, the cable sliding extent could be obtained as the relative distance between the marks and the joint clips. Subsequently, careful examination revealed that H3000 and N3000 exhibited cable sliding at nearly every joint along the cable. Fig. 15 plots the measured sliding extent at each joint and shows that the slip had a gradual decreasing trend from the rupture spot to the farthest side. In the N3000 case, the left-side joints had a larger effect than that of the right-side joints. In addition, the slip extent showed an obvious decreasing trend between L7 and L8 joints in the N3000 test. This change was attributed to the tensioning point located between the joints. Under the sudden impact, the tensioning device slackened, which accounted for the majority of the sliding displacements.

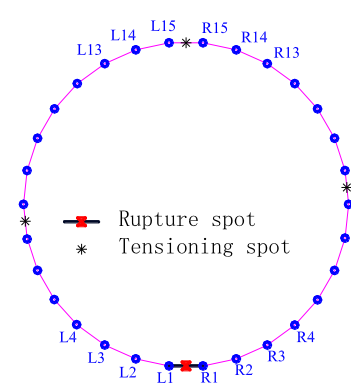

(a) Rolling joint locations

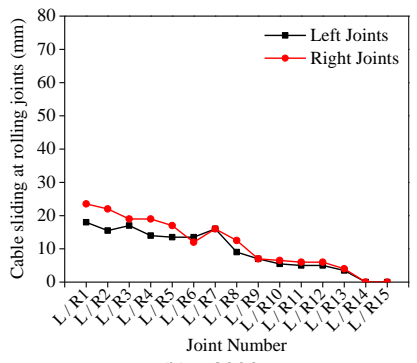

(b) H3000 case

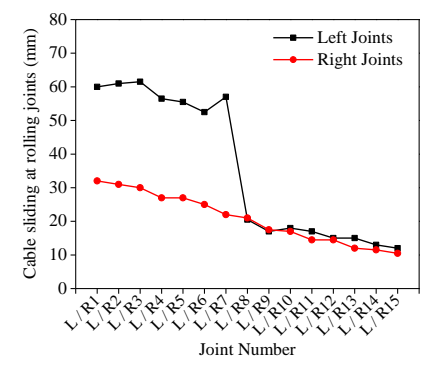

(c) N3000 case
Fig. 15 Residual slip distribution at the rolling joints

Fig. 16 shows a comparison of the internal force reactions at the hoop cable, diagonal struts, and shell members (the component locations are the same as in Figs. 4(d) and 9(a)). In the fully fastened tests, the tension variations at the hoop cable increased with pretension level, but the changing extents were comparatively small. Only in the high-pretension case (A6000) did HS3-1D express an obvious transitory oscillation; this dynamic response was mainly a high-frequency type that dissipated rapidly. H3000 and N3000 showed a dramatic force change at all the four measuring pieces during the rupture, representing a global slackening impact on the entire cable. N3000 also expressed a considerably low-frequency vibration, which might be attributed to the frictional sliding and induced shaking at the rolling joints or related members.

(a)

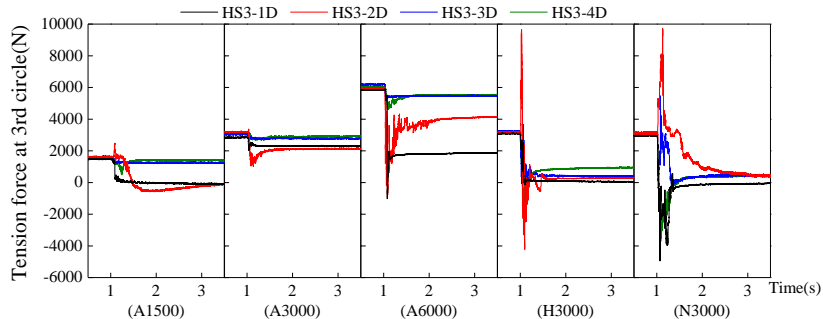

(b)

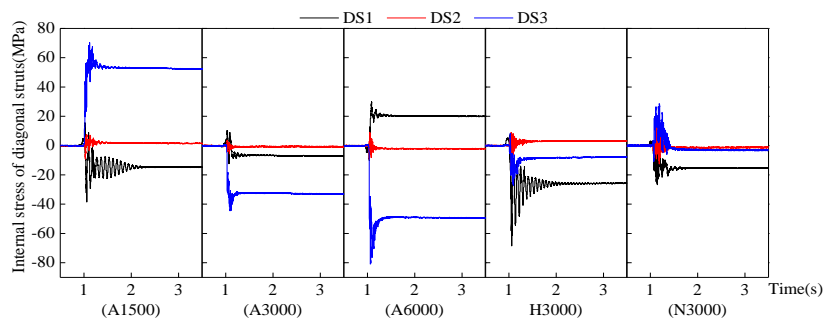

(c)

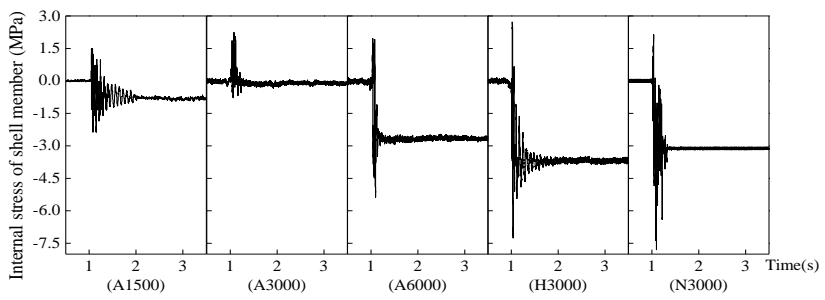

Fig. 16 Dynamic reaction at the structural members: (a) ruptured hoop cable, (b) diagonal struts, and (c) shell member

Given that the stress level at the struts and shell members was small, the initial stress states were greatly affected by the testing or measuring errors, which made distinguishing the real state after cable tensioning difficult. Therefore, as presented in Figs. 16(b) and (c), only the internal force changes were compared, and the initial state of the dynamic responses were set to zero for improved comparison. In the fully fastened group, the internal force 
response at DS1 changed from a tension drop reaction to a tension increase reaction as the pretension level increased. Meanwhile, the internal force response at DS3 varied from an increasing to a decreasing trend. The time duration of the oscillation response was shortened in the high-pretension case. In $\mathrm{H} 3000$ and $\mathrm{N} 3000$, the shrinking and pulling effects of the ruptured cable could not be efficiently resisted by adjacent members because of the weak friction resistance at the rolling joints, thereby leading to a comparatively small inequivalent forces and thus small amplitudes in the oscillatory responses (H3000 and N3000 in Fig. 16(b)). DS2 did not present significant force variation after cable rupture for all test cases, and the oscillatory effects were small.

The slip conditions and cable force varying patterns revealed that sudden rupture and tension failure would be limited to a comparatively small region if the cable-strut joints could effectively resist cable sliding, thereby leading to local failure mode. In this condition, the sub cable-strut system could still effectively support the upper shell, thereby causing only a slight unloading effect and internal force change in the upper shell (A1500 and A3000 in Fig. 16(c)). This unloading effect became intense and led to large amplitude in the dynamic response and an obvious tension decrease at the upper shell member (A6000) as the pretension level increased. However, cable slacking would propagate to a large scope and even to the entire hoop cable range if the cablestrut joints fail to resist the sliding behavior. Large-scale stiffness loss would cause an overall unloading effect on the upper shell, which was reflected as a violent dynamic vibration and internal force loss at the upper shell members (H3000 and N3000 in Fig. 16). Therefore, in practical projects, rolling joints should be fixed and tightened well upon the completion of stretching.

\section{Conclusions}

In this study, experimental tests were conducted on a suspendome to investigate the dynamic responses, failure modes, and mechanical changes under cable rupture failure. Two types of failure conditions were considered. One was the cable break at the static loading state for simulating practical breaking during the in-service period. The other had a single hoop tensioned and ruptured for exploring the presence and effect of cable sliding behavior. From the results and discussion, the following key conclusions could be obtained.

1) The proposed tensioning, measuring, and rupturing devices were suitable for rupture tests on suspendomes. The use of high-speed camera and dynamic strain amplifiers could effectively monitor the transient breaking process and dynamic responses.

2) The suspendome had excellent stiffness and robustness, and therefore no obvious deflection or shaking were observed. The reactions caused by cable rupture at the outmost circle (the first hoop) were more obvious than that at the inner circle (the third hoop). Rolling joints could effectively reduce joint friction loss during the stretching process and could resist unbalanced cable tension during static loading. However, under cable rupture, cable sliding still occurred and could influence the oscillatory response and cable tension recovery patterns. The DAFs of struts connected to the rupture cable ends were scattered and high. Thus, special attention or significant safety insurance should be considered for diagonal struts.

3) The single hoop-tensioned and ruptured tests indicated that, when joint frictional resistance was certain, the oscillation intensity and impact-affected region increased with the initial tension levels. If cable-strut joints could effectively fix the hoop cable, then cable breaking effect would be limited to a comparatively small region, thereby creating a local failure mode. If the frictionresisting capability of the cable-strut joints was weak, then cable slacking would propagate to a large scope, thereby creating an overall unloading effect.

\section{Acknowledgments}

This research was sponsored by the National Natural Science Foundation of China (Grant No. 51478310) and Project of Tianjin Urban \& Rural Construction Commission (2014-1). The authors also appreciate the financial support provided by the China Scholarship Council (File No.201606250065) that enables the Visiting Scholar Research at Columbia University at New York, United States.

\section{References}

[1] Kawaguchi M., Abe M. and Hatato T., "On a Structural System 'Suspen-dome' System", Proceedings of the IASS-MSU International Symposium, Istanbul, Turkey, May 24-28, 1993.

[2] Guo J.M., Dong S.L. and Yuan X.F., "Research on static property of suspen-dome structure under heap load", Advanced Steel Construction, 8(2), 137-152, 2012.

[3] Liu H.B., Han Q.H., Chen Z.H., Wang X.D., Yan R.Z. and Zhao B., "Precision control method for pre-stressing construction of suspen-dome structures", Advanced Steel
Construction, 10(4), 404-425, 2014.

[4] Chen Z.H., "Beam String Structure System", Beijing, China, Science Press, 2013. (in Chinese)

[5] Wang X.X., Yu Y.J. and Yan X.Y., "Theoretical model of symmetric wire breaks in semiparallel wire cables", Journal of Tianjin University (Science and Technology), 49(S1), 3440, 2016.

[6] Kang W.J., Chen Z.H., Lam H.F. and Zuo C.R., "Analysis and design of the general and outmost-ring stiffened suspen-dome structures", Engineering Structures, 25(13), 1685$1695,2003$.

[7] Cao Q.S. and Zhang Z.H., "A simplified strategy for force finding analysis of suspendomes", Engineering Structures, 32(1), 306-318, 2010.

[8] Chen Z.H., Yan R.Z., Wang X.D., Liu H.B. and Xiao X., "Experimental researches of a suspen-dome structure with rolling cable-strut joints", Advanced Steel Construction, 11(1), 15-38, 2015.

[9] Liu H.B. and Chen Z.H., "Research on effect of sliding between hoop cable and cable-strut joint on behavior of suspen-dome structures", Advanced Steel Construction, 8(4), 359-365, 2012.

[10] Wang S., Zhang G.J. and Zhang A.L., "The prestress loss analysis of cable strut joint of the Badminton Gymnasium for 2008 Olympic Games", Journal of Building Structures, 6, 3944, 2007

[11] Zhang Z.H., Cao Q.S., Dong S.L. and Fu X.Y., "Structural design of a practical suspendome", Advanced Steel Construction, 4(4), 323-340, 2008.

[12] Wang F. and Bai J.T., "Dynamic effects on a pre-stressed multi-story plane steel frame caused by sudden failure of a cable", Advanced Materials Research, 671, 441-445, 2013.

[13] Gerasimidis S. and Baniotopoulos C.C., "Disproportionate collapse analysis of cablestayed steel roofs for cable loss", International Journal of Steel Structures, 11(1), 91-98, 2011.

[14] Chen Z.H. and Sun G.J., "Research on the stability of suspen-dome after cables failure", Spatial Structures, 18(1), 46-50, 2012.

[15] Zhu M.L., Dong S.L. and Yuan X.F., "Failure analysis of a cable dome due to cable slack or rupture", Advances in Structural Engineering, 16(2), 259-271, 2013.

[16] Wang H.J., Fan F., Qian H.L., Zhi X.D. and Zhu E.C., "Analysis of pretensioning construction scheme and cable breaking for megastructure suspend-dome", Journal of Building Structures, S1, 247-253, 2010.

[17] Liu R.J., Li X., Xue S.D., Mollaert M. and Ye J., "Numerical and experimental research on annular crossed cable-truss structure under cable rupture", Earthquake Engineering and Engineering Vibration, 16(3), 557-569, 2017.

[18] Wolff M. and Starossek U., "Cable loss and progressive collapse in cable-stayed bridges", Bridge Structures, 5(1), 17-28, 2009

[19] Mozos C.M. and Aparicio A.C., "Parametric study on the dynamic response of cable stayed bridges to the sudden failure of a stay, Part I: bending moment acting on the deck", Engineering Structures, 32(10), 3288-3300, 2010.

[20] Russell J.M., Owen J.S. and Hajirasouliha I., "Experimental investigation on the dynamic response of RC flat slabs after a sudden column loss", Engineering Structures, 99, 28-41, 2015. 